\title{
Fracture Mechanisms in Dual-Phase Steel: Influence of Martensite Volume Fraction and Ferrite Grain Size
}

\author{
D. Avendaño-Rodríguez ${ }^{1}$, J.D. Granados ${ }^{2}$, E. Espejo-Mora ${ }^{2}$, L. Mujica-Roncery ${ }^{3}$ and R. Rodríguez- \\ Baracaldo ${ }^{1}$ \\ ${ }^{1}$ Universidad Nacional de Colombia - Bogotá, Grupo Innovación de Procesos de Manufactura e Ingeniería de Materiales. - Bogotá \\ D.C, Colombia. \\ ${ }^{2}$ Universidad Nacional de Colombia - Bogotá, Grupo Análisis de falla e Ingeniería de Superficies. Bogotá D.C, Colombia. \\ ${ }^{3}$ Universidad Pedagógica y Tecnológica de Colombia, Grupo de Investigación en Materiales Siderúrgicos e INCITEMA, Boyacá, \\ Colombia.
}

Received 30 October 2018; Accepted 29 December 2018

\begin{abstract}
The influence of Martensite Volume Fraction (MVF) on fracture mechanisms in a Dual Phase steel with two different grain sizes was studied in this work. Ferrite-Martensite microstructure was obtained by an intercritical heat treatment for both groups of grain sizes. The results show a direct relationship between a higher temperature during the intercritical heat treatment and the increase of the MVF. The fine microstructure with higher MVF presents a high tensile strength and a good ductility. Furthermore, in relation to the material behavior under impact conditions, grain refinement and higher values of MVF promote ductile fracture by typical microvoid coalescence. High values of impact energy refer to the presence of low-carbon martensite formed at higher temperatures, which is more ductile than high carbon martensite formed at lower temperatures. Additionally, fine-grained materials have a better ability to dissipate impact energy. It was shown that an increase of $10.0 \%$ in MVF allows fine grain microstructures to improve their capacity to dissipate impact energy by $11.4 \%$. This behavior may be explained because of the low carbon content of the as-received material, and the mechanical properties of the martensite obtained by the intercritical heat treatment.
\end{abstract}

Keywords: Martensite, Fracture, Impact toughness, Dual-Phase Steel.

\section{Introduction}

Dual Phase (DP) steels are classified into a relatively recent family of steels called Advanced High Strength Steels (AHSS) because, despite their low content of alloying elements, they exhibit a high level of strength with a good combination of toughness and ductility. DP steels are characterized by a ferritic-martensitic or ferritic-bainitic microstructure depending on their chemical composition and heat treatment $[1,2]$. This combination of phases has the capacity to keep the high strength of the steel with a high level of ductility compared with other mild steels; also, these kinds of steels have continuous yielding behavior [3] in such a way that these steels are often used in automotive and airline industries for making lighter structural components [4].

Different studies have demonstrated that the mechanical properties of the dual phase structure depends on the ferrite grain size and Martensite Volume Fraction (MVF) [5]. MVF can be modified by adjusting the heating temperature of the steel in the intercritical region by changing the amount of carbon in the steel, and increasing the cooling rate [6]. Different methods to determine the Ac1 and Ac3 temperatures, such as dilatometry, empirical relationships, and measures of MVF directly as a function of intercritical temperature, have been considered to obtain the correct temperatures for the intercritical heat treatment.. The addition of alloying elements like $\mathrm{Nb}, \mathrm{V}$, and Mo rises the hardenability of ferrite, and promotes MVF increment and grain refinement by the formation of carbides on grain boundaries inhibiting the grain growth [7]. Phase grain size is an important factor on the fracture mechanics of dualphase steels. Small martensite grains allow the free glide and uniform dislocations distribution during plastic deformation resulting in high ductility, and finer martensite in a precipitate-free ferrite matrix representing a tough microstructure $[8,9]$.

Experimental, theoretical, and numerical studies of the relationship between the fracture mechanisms and the microstructural features in DP steels have been reported in the literature. It can be found that the tensile properties improve by decreasing the martensite grain size, affecting the form in which martensite cracks propagate and fracture $[10,11]$. In the necked region of the tensile specimen, microvoids form in three specific places: martensite-ferrite interface, martensite grains, and inclusions [12]. Nevertheless, the fracture mechanisms on impact test specimens or fracture toughness specimens have not been fully understood. The aim of this study is to determine the relationship between the fracture mechanisms and the MVF on the Charpy impact test. 


\section{Experimental Procedure}

As received, the material was provided in a hot rolled condition with a ferrite-pearlite fine grained microstructure. Its chemical composition, determined by optical emission spectrometry, was $0.15 \% \mathrm{C}, 1.05 \% \mathrm{Mn}, 0.41 \% \mathrm{Si}, 0.04 \% \mathrm{~S}$ and $\mathrm{Fe}$ balance. To obtain a coarse grain on one of the samples sets, the as-received DP steel was subjected to one hour holding period at austenitizing temperature $\left(900^{\circ} \mathrm{C}\right)$ and air cooling. Additionally, to get different MVFs, several intercritical annealing treatments were made on impact and tensile specimens. The intercritical range (between $\mathrm{Ac}_{1}$ and $\mathrm{Ac}_{3}$ ) were selected according to the literature and prior experimentation. To find the best heat treatment parameters, the tested material was subjected to six temperatures in the intercritical region ranging from $750{ }^{\circ} \mathrm{C}$ to $850{ }^{\circ} \mathrm{C}$ changing every $20^{\circ} \mathrm{C}$ done in an electrical furnace without protective atmosphere followed by water quenching. The entire heat treatment process is illustrated in figure 91. Fine and coarse grain specimens were subjected to intercritical annealing at two different temperatures that were chosen to cover a specific range inside the intercritical zone that assures significant differences in the MVF.

After the heat treatment process, all the samples were prepared by standard mechanical grinding and polishing procedures, finishing with $1 \mu \mathrm{m}$ alumina polishing. To reveal the microstructure, the samples were additionally etched in $2 \%$ Nital for $10 \mathrm{~s}$. The optical micrographs were taken by Olympus LECO IA32 microscopy. The method of intercepts was used to quantify the average size of each phase, and area fraction of martensite was obtained using the image processing software, ImageJ. Fracture surface images was carried out by FEI Quanta 200 scanning electron microscope (SEM).
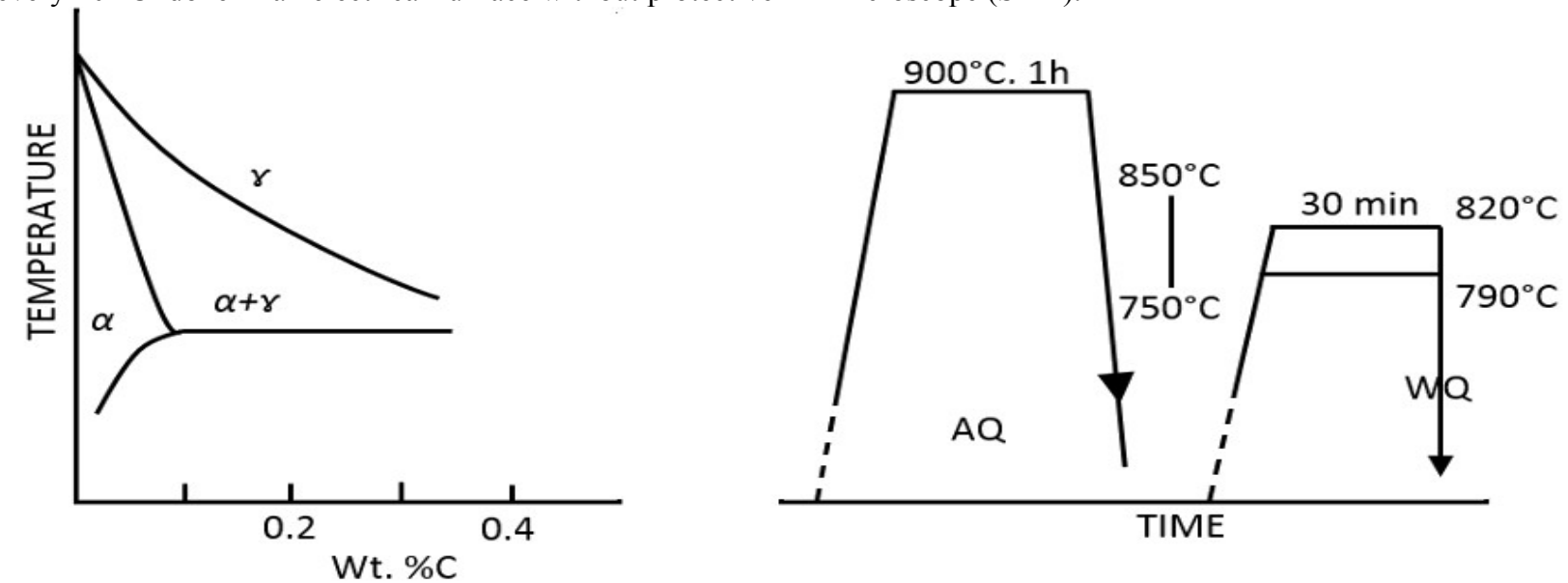

Fig. 1. Schematic representation of intercritical heat treatments and quenching.

Charpy impact and tensile specimens were subjected to an intercritical heat treatment at $790^{\circ} \mathrm{C}$ and $820^{\circ} \mathrm{C}$, and then quenched in water at room temperature. The Charpy impact test was carried out in a $300 \mathrm{~J}$ pendulum machine. Charpy impact sub-sized test specimens $(3.5 \times 10 \times 55 \mathrm{~mm})$ were cut by water jet and the $45^{\circ}$ Charpy $\mathrm{V}$ notch by milling according to ASTM E23-16b standard [13]. The tensile tests were conducted on a Shimadzu UH-500kNI universal test machine of $500 \mathrm{kN}$ and the strain was measured with an Epsilon 3542 axial extensometer. The tensile sample nominal dimensions were the following: $50 \mathrm{~mm}$ in gauge length, $12.5 \mathrm{~mm}$ in width, and $3.4 \mathrm{~mm}$ in thickness. The tests were performed at room temperature and cross head speed of $10 \mathrm{~mm} / \mathrm{min}$. The yield strength was defined as the stress corresponding to $0.2 \%$ plastic strain. Hardness test were conducted in Rockwell B scale using a tungsten carbide ball indenter (HRBW).

\section{Results and Discussion}

\subsection{Microstructural Analysis}

In the first part of the study, the test material was subjected to six different temperatures with the aim to determine the best intercritical temperatures for impact toughness by verifying the MVF variability. The change on MVF was made by varying the intercritical temperature where the austenite content increases at higher temperatures. Also, increasing the cooling rate from the ferrite-austenite region promotes the martensite formation [6].
The resulting microstructure in the specimens after the intercritical treatment consists of a combination of ferrite and martensite phases. Martensite is achieved by the rapid cooling of the test specimens from the intercritical temperature. As mentioned before, the MVF depends of three principal factors: heating temperature, carbon content, and cooling rate. The quality of the martensite formed is important as well, which is quantified by the hardenability. This quality can be influenced by chemical composition, temperature, and heating time. In the process of austenite formation during the intercritical heat treatment, it has been found that the first stage of austenite formation is the rapid austenite growth from perlite until its complete dissolution. Then, in the second stage, the slow growth of austenite inside the ferrite phase is controlled by the carbon diffusion in austenite at higher temperatures and the manganese diffusion in ferrite at lower temperatures. Finally, austenite formation takes place in a slow process of equilibrium of ferrite and austenite at a rate controlled by manganese diffusion in austenite which, in practice, can be controlled by the soaking time [1, 14]. Previous work [7] has shown that the manganese content is decisive to obtain a fine grain ferrite / martensite microstructure. Mn content of $1.05 \%$ of this steel mainly improves grain size stability during intercritical annealing by lowering the Ac1 temperature and the critical cooling rate. Also, Mn content causes a more efficient pinning effect by refining cementite and reducing the grain boundary mobility by solute drag. Likewise, the enrichment of $\mathrm{Mn}$ in the cementite that is inherited by austenite increases its hardening capacity because $\mathrm{Mn}$ 
retards the proeutectoid ferrite, pearlite, and bainite formation $[7,14]$.

Figure 2 shows the MVF evolution as a function of temperature, displaying a continuous increment of martensite around ferrite grains with the increase of the intercritical temperature. Ferrite boundaries and triple points are the preferred sites for austenite nucleation, but, at higher temperatures of the intercritical treatment, the martensite starts to grow inside ferrite grains. It is necessary to remember that other crystal defects like no-metallic inclusions and segregations are potential sites for phase nucleation because they have a higher energy state [15].
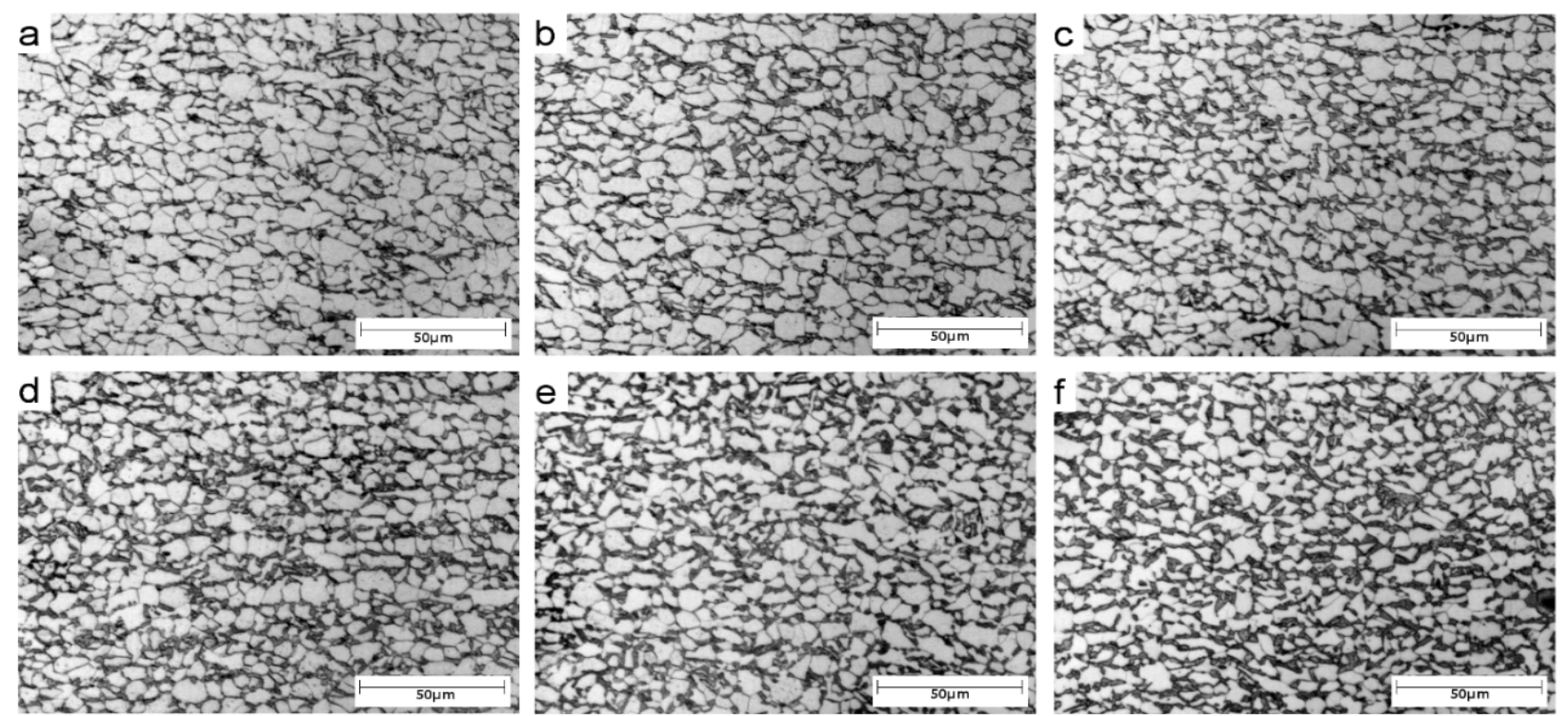

Fig 2. Optical Micrographs of specimens under intercritical annealing and quenching at a) $750^{\circ} \mathrm{C}$, b) $770^{\circ} \mathrm{C}$, c) $790^{\circ} \mathrm{C}$, d) $810^{\circ} \mathrm{C}$, e) $830^{\circ} \mathrm{C}$, f) $850^{\circ} \mathrm{C}$.

Table 1 shows the MVF results and figure 3 shows the microstructure of Charpy impact specimens. Coarse grain specimens with an average grain size of $20 \mu \mathrm{m}$ resulted in $10.9 \%$ and $22.4 \%$ MVF for the intercritical temperatures of $790^{\circ} \mathrm{C}$ and $820^{\circ} \mathrm{C}$, respectively. Fine grain specimens with average grain size of $8 \mu \mathrm{m}$ resulted in $13.9 \% \mathrm{MVF}$ for $790^{\circ} \mathrm{C}$ and $23.7 \% \mathrm{MVF}$ for $820^{\circ} \mathrm{C}$. In the fine grain specimens, the ferrite grain shape is equiaxed. Likewise, the previous normalizing heat treatment promotes a regular
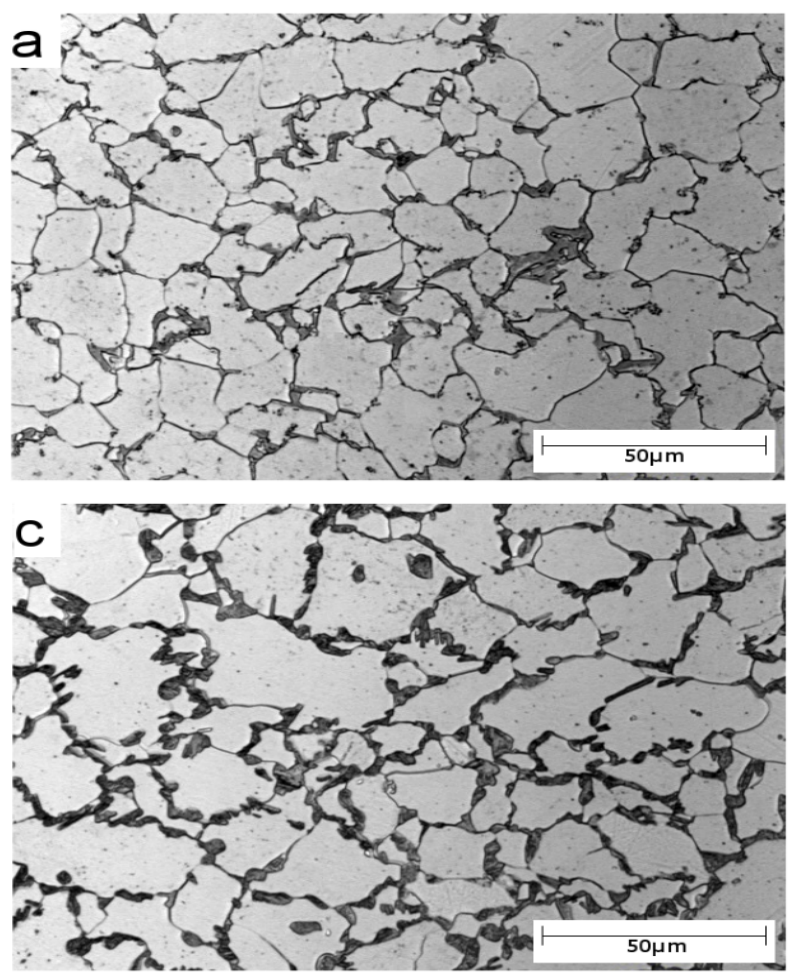

microstructure for the coarse grain specimens. Martensite distribution occurs in a continuous network along the prior austenite grain boundaries with an acicular morphology. Moreover, the prior austenite nucleates at grain boundaries and triple points, and its distribution takes place along the ferrite grain boundaries, but, at higher temperatures of intercritical heat treatment, martensite islands begin to appear within the ferrite grain; Peng and Preban [16] and Rosenberg et al. [17] report similar relationships

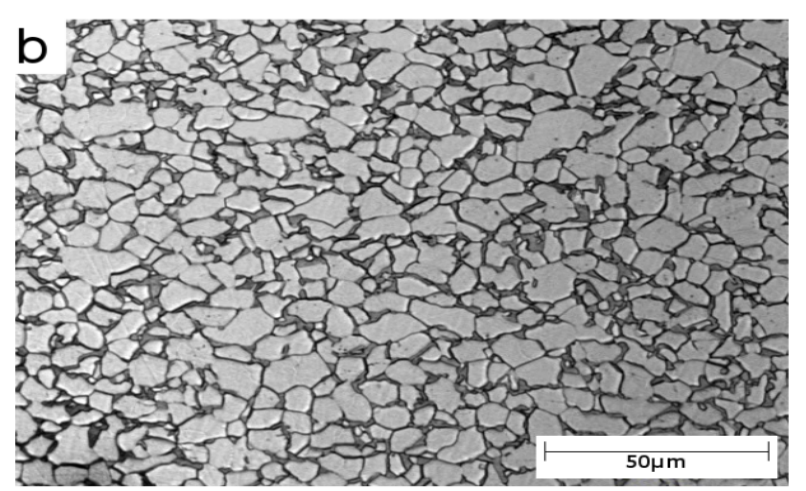

Fig 3. Optical Micrographs of impact test specimens under intercritical annealing and quenching at $790^{\circ} \mathrm{C}$ for a) coarse grain and b) fine grain and at $820^{\circ} \mathrm{C}$ for $\mathrm{c}$ ) coarse grain and d) fine grain.

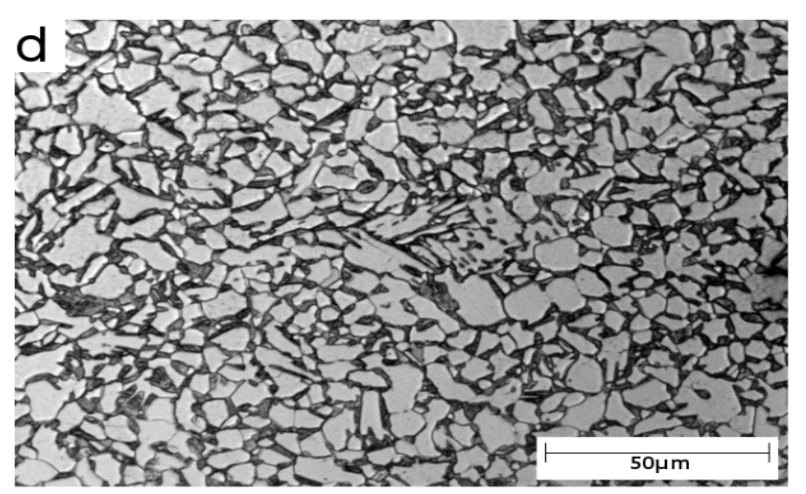




\subsection{Tensile test}

Figure 4 shows the engineering stress/strain curves of the DP steels. For all of the samples, a continuous yielding behavior can be observed without any distinct evidence of a yield point phenomenon. Tested DP steels exhibit low elastic limit and continuous yielding, Zhao et al. point out that this behavior is produced by the presence of mobile dislocations at the ferrite-martensite interface induced by the volume expansion during austenite-martensite transformation. Furthermore, the transition from the elastic to plastic regime is caused by the deficiency of mobile dislocations, which is related with volume fraction and morphology of martensite [18].

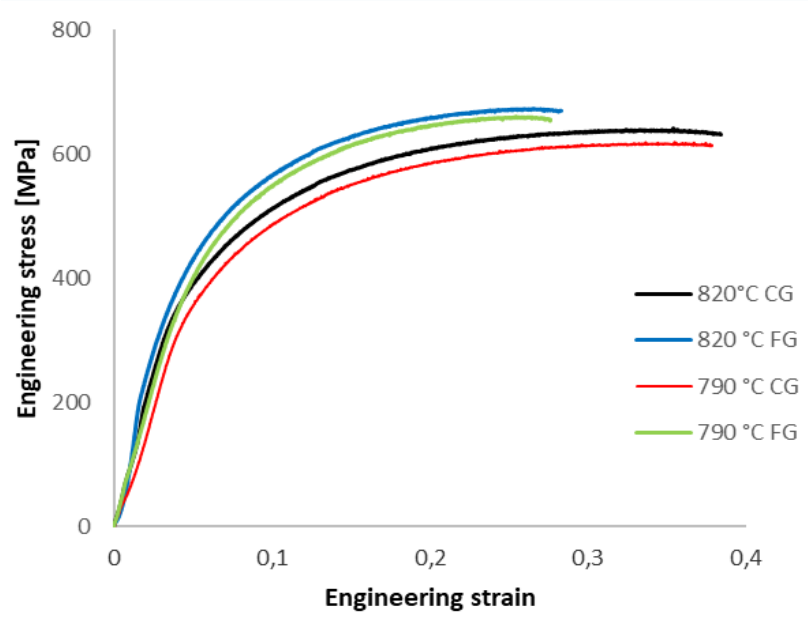

Fig 4. Engineering stress/engineering strain curves of the DP steels

The yield strength of these steels increases with higher intercritical annealing temperatures. This trend is related to the mobile dislocations in grains, which have a direct relationship with the ferrite volume fraction and grain size . The ultimate tensile strength has a combined effect between grain size, volume fraction of the constituent phases and their hardness. According to several works, MVF has two contradicting effects on the tensile strength. First, a higher martensite volume fraction increases the tensile strength because of the rise of volume fraction of the hard phase. Nevertheless, carbon content of the martensite phase decreases with increasing volume fraction of the martensite because of the partition of the carbon content among the phases at high intercritical temperature. The hardness of the martensite is mainly determined by the carbon content and tempering degree [16, 19]. Consequently, the ultimate tensile strength of the tested samples on this research decreases with the reduction of intercritical temperature, mainly because of the martensite content. It has been found that effect of ferrite grain size on yield strength is much stronger than on tensile strength leading to a decrease of the yield to tensile ratio with increasing ferrite grain size. Additionally, the total elongation increases with the increase in grain size, which can be explained by a more ductile matrix with less restriction to the dislocations glide.

The product of tensile strength and elongation, also called static toughness, is a comprehensive performance which characterizes the level of strength and toughness. It is approximately equal to the area below the stress-strain curve for a given strain level equal to the energy absorbed by the sample in the tensile testing process. The steel with fine grain and intercritical temperature of $820^{\circ} \mathrm{C}$ has the highest value of static toughness, showing a high level of strength and toughness, which means high fracture toughness.

Martensite with low carbon content increases dual-phase steel ductility. Nevertheless, a further increase in the MVF changes the matrix structure dramatically, resulting in material brittleness likewise happening with the martensite grain coarsening. So, the total elongation gradually decreases with further increase in intercritical temperature [20].

\subsection{Impact Toughness}

Hardness measurements of Charpy impact specimens with intercritical treatment resulted in higher hardness values for fine grain specimens and lower hardness values for coarse grain specimens. For each group of grain sizes, hardness increases with the temperature, resulting in $85.7 \mathrm{HRBW}$ and 89.0 HRBW for coarse grain specimens treated at $790^{\circ} \mathrm{C}$ and $820^{\circ} \mathrm{C}$, respectively. For fine grain specimens, hardness was 91.2 $\mathrm{HRBW}$ for $790^{\circ} \mathrm{C}$ and $93.7 \mathrm{HRBW}$ and $820^{\circ} \mathrm{C}$ of intercritical treatment (Fig. 5).

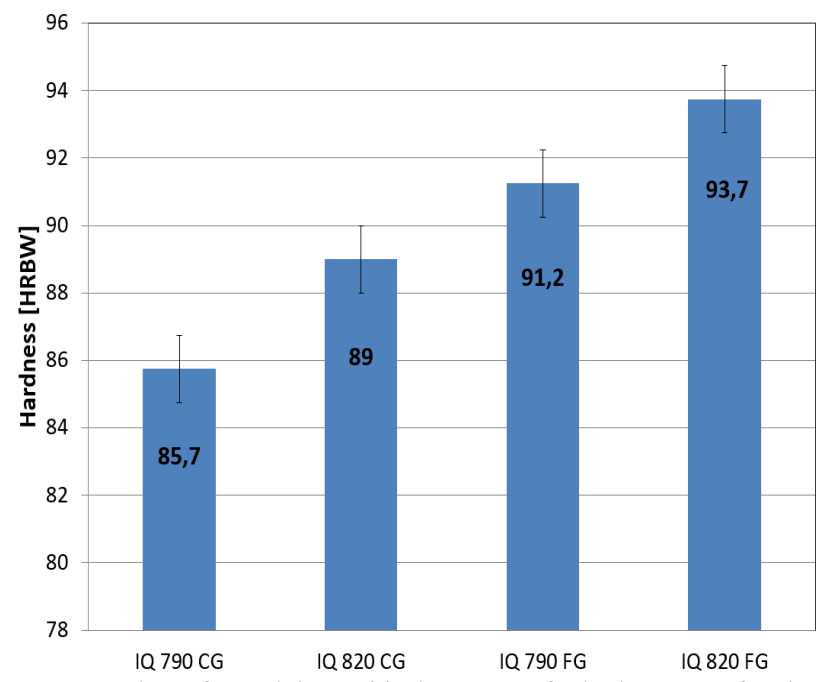

Fig 5. Hardness for each intercritical treatment for both groups of grain sizes.

Results of the Charpy impact energy have the same trend as that observed in hardness measurements, having in this case a slightly continuous increase of impact energy average for both grain size groups of specimens (Fig 6). Coarse grain steels had the lower values of impact energy with $30.6 \mathrm{~J}$ and $35.9 \mathrm{~J}$ for $790^{\circ} \mathrm{C}$ and $820^{\circ} \mathrm{C}$ intercritical temperature. Fine grain steels had $36.7 \mathrm{~J}$ for $790^{\circ} \mathrm{C}$ and $40.9 \mathrm{~J}$ for $820^{\circ} \mathrm{C}$ intercritical temperature. In comparison with some previous studies, it has found out that in a AISI/SAE 4340 steel the main values of absorbed energy are $57.0 \mathrm{~J}$ for a dual-phase with tempered bainite-ferrite microstructure, which is the one with the highest toughness. Followed by $36.0 \mathrm{~J}$ for bainite-ferrite microstructure, $20.0 \mathrm{~J}$ for a whole bainite microstructure, 11.0 J for martensite-ferrite, and, finally, 3.6 $\mathrm{J}$ for full martensite microstructure [21, 22]- all measurements were taken at room temperature. Although the tested steel on this study has ferrite-martensite microstructure, the absorbed energy at room temperature tends to be higher in contrast to the mentioned studies. The reasons for these differences are the carbon content, the MVF, and the quality of the obtained martensite. 


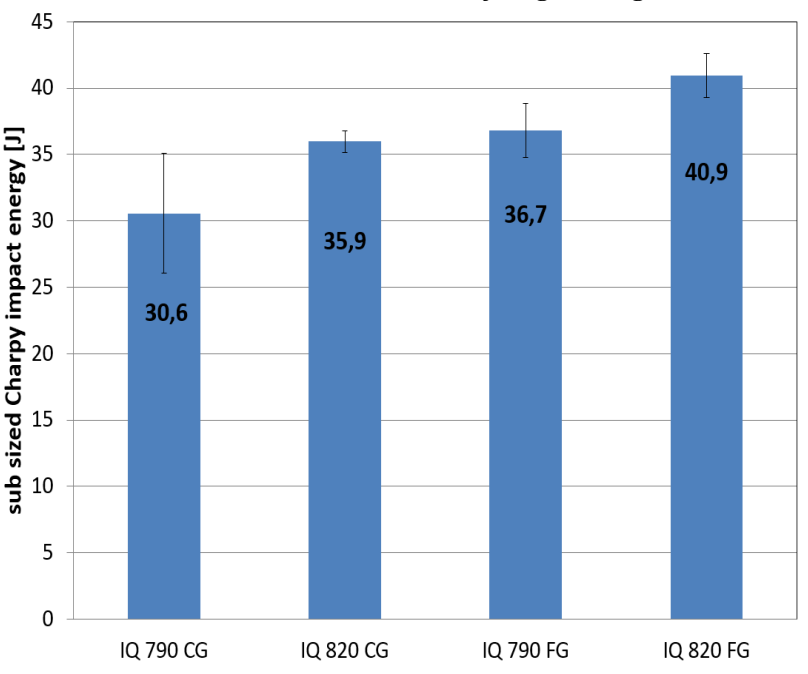

Fig 6. Sub-sized Charpy impact energy for each intercritical treatment for both group of grain sizes.

According to hardness and impact energy measurements, an increment in MVF promotes higher values in mechanical strength and toughness, contrary to the behavior of a fully martensitic steel in which the increment in strength is accompanied by a decrement in ductility and toughness. This fact can be explained by martensite quality; as mentioned above, the martensite quality depends on the austenite hardenability and this feature depends on the carbon content. Heating temperature determines the carbon content of austenite and the MVF. During the heating process, just above of critical temperature Ac1, the austenite fraction is small and has high carbon content, where the resulting martensite after rapid cooling becomes hard and brittle. At higher temperatures, the MVF rises, but the carbon content in austenite is lower, promoting low hardenability and therefore an improvement in ductility and toughness. This suggests that, from the quantitative point of view, the carbon content is the key parameter that controls the deformation properties and the total quantity of energy release $[17,23$, 24]. Furthermore, other researchers have found that when the MVF decreases, it is expected that the connectivity of martensite will decrease, resulting in better impact properties, but the role of grain size and carbon enrichment of martensite have a drastic effect on notched impact energy $[25,26]$. An estimation of the martensite carbon content can be obtained by using the well-known law of mixtures, equation1 [27]:

$C=C_{f} V_{f}+C_{m} V_{m}=C_{f}\left(1-V_{m}\right)+C_{m} V_{m}$

where $\mathrm{C}$ and $\mathrm{V}$ represent the mean carbon content and volume fraction of a specifically phase, respectively. $\mathrm{f}$ and $\mathrm{m}$ subscripts mean ferrite and martensite respectively, and $\mathrm{C}$ is the mean carbon content of the steel. The supersaturated limit of carbon content in ferrite phase is $0.015 \mathrm{wt} \%$, therefore, assuming this value for $C_{f}$ and $0.15 \%$ for $C$, the values in table 1 are obtained. As shown, regardless of the final grain size, at the same temperature heat treatment, the mean martensite carbon content is approximately equal. On the other hand, the impact energy increases with the reduction of the average carbon content in the martensite phase. It is important to note also that the role of grain size is important because the microstructure refinement promotes an increase in mechanical strength and toughness.

Table 1. Mechanical properties and microstructure of specimens treated

\begin{tabular}{|c|c|c|c|c|c|c|}
\hline Designation & Treatment & $\begin{array}{c}\text { Ferrite grain } \\
\text { size average } \\
{[\mu \mathrm{m}]}\end{array}$ & MVF $\pm \mathbf{s}[\mathbf{v} \%]$ & $\begin{array}{l}\text { Hardness } \\
\text { [HRBW] }\end{array}$ & $\begin{array}{c}\text { Impact } \\
\text { energy }[\mathbf{J}]\end{array}$ & $\begin{array}{c}\text { Mean } \\
\text { martensite } \\
\text { carbon } \\
\text { content } \\
\text { [wt. } \%]\end{array}$ \\
\hline $790 \mathrm{CG}$ & $\mathrm{A}+\mathrm{IQ}$ & $19.12 \pm 3.39$ & $10.9 \pm 1.8$ & 85.7 & 30.6 & 0.027 \\
\hline $820 \mathrm{CG}$ & $\mathrm{A}+\mathrm{IQ}$ & $20.03 \pm 4.98$ & $22.4 \pm 0.36$ & 89.0 & 35.9 & 0.021 \\
\hline $790 \mathrm{FG}$ & $\mathrm{N}+\mathrm{IQ}$ & $7.36 \pm 1.97$ & $13.9 \pm 0.67$ & 91.2 & 36.7 & 0,025 \\
\hline $820 \mathrm{FG}$ & $\mathrm{N}+\mathrm{IQ}$ & $8.72 \pm 2.16$ & $23.7 \pm 1.25$ & 93.7 & 40.9 & 0,021 \\
\hline
\end{tabular}

\subsection{Fracture Surface Analysis}

Fractography studies on CVN sub-sized specimens were conducted through stereoscopy and fracture mechanisms analysis by SEM. Figure 7 shows fracture surfaces of a representative Charpy impact specimen of each heat treatment and grain sizes set. The fracture surface of impact test samples is characterized by the presence of four zones: near the notch exist a fracture region were the content initially cracks; after that, an unstable fracture region, typically identified by the existence of radial marks, appears. On each side of the previous region, the sample exhibits shear lips with a covered area proportional to the ductility of the material. Finally, the sample presents a final fracture region. For the specimens with coarse grain and lower MVF, the greater portion of fracture area surface corresponds to brittle fracture (Fig. 7a). In the specimens with coarse grain and higher MVF, the area of brittle fracture decreases, and the area of ductile fracture or shear lips increases (Fig. 7c). In specimens with fine grains, the same situation slightly occurs for the fracture surface areas, where the brittle fracture mechanism is inversely proportional to the intercritical heat treatment with clear evidence of radial marks on the unstable fracture region which point to the crack initiation sites on the fracture initiation zone. In the same way, the area portion that occupies shear lips increases when the MVF increases (Fig. 7b and 7d). Consequently, these results are coherent with the Charpy impact energy measured because brittle fracture uses less dissipation energy than ductile fracture.

Figure 8 shows the fracture micromechanism of each specimen analyzed surface by SEM, indicating the brittle region of Charpy impact specimens for each treatment and both sets of grain sizes. The main fracture mechanism is cleavage (black arrows) with some portions of ductile fracture with microvoids (white arrows). At a macroscale, the fracture surface of fine grain specimens presents a slight difference between the brittle area of each sample with different MVF. Figure $8 \mathrm{~b}$ shows that the brittle fracture area presents a mixed fracture mechanism by primarily cleavage and microvoids, but, at a higher MVF with similar grain 

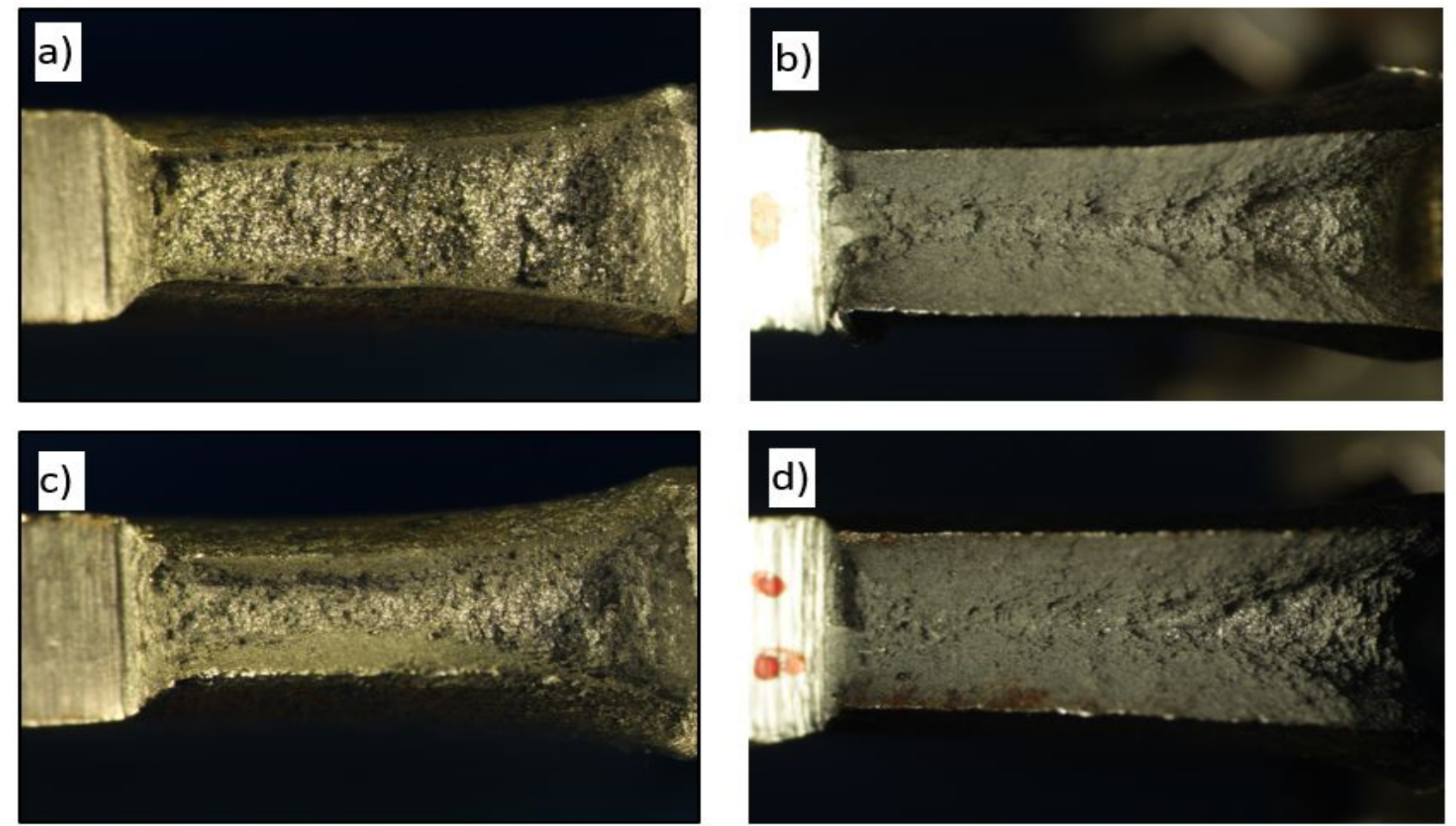

Fig 7. Charpy impact specimens fractographies after intercritical quenching at $790^{\circ} \mathrm{C}$ for a) coarse grain and b) fine grain and at $820^{\circ} \mathrm{C}$ for c) coarse grain and d) fine grain.
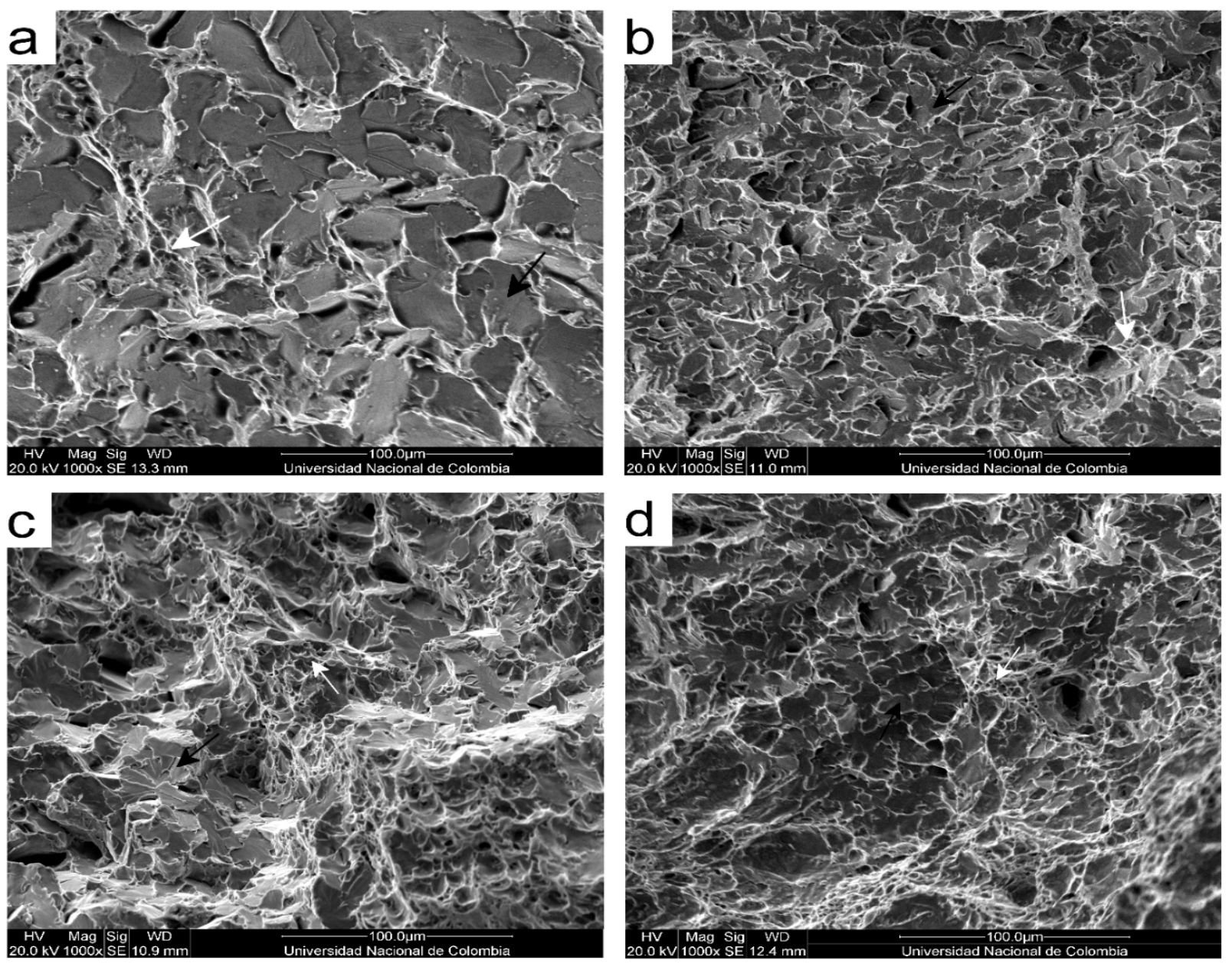

Fig 8. SEM fractographies of Charpy impact specimens after intercritical quenching at $790^{\circ} \mathrm{C}$ for a) coarse grain and b) fine grain and at $820^{\circ} \mathrm{C}$ for c) coarse grain and d) fine grain. 
Similar relationships have also been reported by other researchers. The effect of microstructure refinement suppresses brittle fracture and increase the development of large voids during ductile fracture. Usually, the brittle fracture of DP steels is attributed to an interconnected martensite network and to a coarse microstructure [18]. When the coarse microstructure is present, the martensitic phase increases its size also, producing larger initial cracks in the fragile phase. This interconnected martensite restricts the plastic deformation by confining the sliding systems and by promoting a triaxial state of stress. Once the martensite fractures, cracks can propagate through the preferential planes near the fracture region of the martensite [ $28-30]$.

\section{Conclusions}

- All samples, regardless of the grain size and MVF, show a continuous-yielding behavior with high workhardening in contrast with a hypoeutectoid steel with ferritic-perlitic microstructure. Coarse grain size increases the ductility, but it reduces the tensile strength while the opposite effect can be observed with a finer microstructure.

- There is a direct relationship between the increase of the intercritical heat treatment temperature and the increase of the MVF; moreover, the fine microstructure with higher MVF presents a high tensile strength and a good ductility.

- In relation to the material behavior under impact conditions, it can be observed that the microstructure plays a important role. Fine-grained materials have a better ability to dissipate impact energy; moreover, the increase of MVF allows an increase in the mechanical behavior. The results of this study show that a $10.0 \%$ increase in the MVF allows fine grain microstructures to increase their capacity to dissipate impact energy by $11.4 \%$. This result can be explained because of the low carbon content at the as-received material and the mechanical properties of the martensite obtained by the intercritical heat treatments.

- The impact test shows that grain refinement and high MVF promote ductile fracture by typical micro voids coalescence.

- Low values of impact energy are related to the presence of high levels of carbon in martensite formed at lower intercritical temperatures, which are more brittle than low carbon martensite formed at higher temperatures.

This is an Open Access article distributed under the terms of the Creative Commons Attribution License

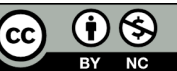

\section{References}

[1] M. S. Rashid, "Dual Phase Steels," Annu. Rev. Mater. Sci. 11, 1: 245-266, 1981.

[2] R. G. Davies, "Influence of martensite composition and content on the properties of dual phase steels," Metall. Trans. A. 9, 5: 671679, 1978.

[3] B. Grushko and B. Z. Weiss, "Yield behaviour of dual-phase steel," Scr. Metall. 23, 6: 865-870, 1989.

[4] F. Hayat and H. Uzun, "Effect of Heat Treatment on Microstructure, Mechanical Properties and Fracture Behaviour of Ship and Dual Phase Steels," J. Iron Steel Res. Int. 18, 8: 65-72, 2011.

[5] E. Erişir and O. G. Bilir, "Effect of intercritical annealing temperature on phase transformations in medium carbon dual phase steels," J. Mater. Eng. Perform. 23, 3: 1055-1061, 2014.

[6] A. Ghaheri, A. Shafyei, and M. Honarmand, Effects of inter-critical temperatures on martensite morphology, volume fraction and mechanical properties of dual-phase steels obtained from direct and continuous annealing cycles, Mater. Des. 62: 305-319, 2014.

[7] M. Calcagnotto, D. Ponge, and D. Raabe, "On the effect of manganese on grain size stability and hardenability in ultrafinegrained ferrite/martensite dual-phase steels," Metall. Mater. Trans. A Phys. Metall. Mater. Sci. 43, 1: 37-46, 2012.

[8] A. Bag, K. K. Ray, and E. S. Dwarakadasa, "Influence of martensite content and morphology on tensile and impact properties of high-martensite dual-phase steels," Metall. Mater. Trans. A, 30, 5: 1193-1202, 1999.

[9] T. D. Isfahani, A. Shafyei, and H. Sharifi, "Impact and tensile properties of ferrite-martensite dual-phase steels," Fatigue Fract. Eng. Mater. Struct. 32, 2: 141-147, 2009.

[10]E. Ahmad, T. Manzoor, M. M. A. Ziai, and N. Hussain, "Effect of martensite morphology on tensile deformation of dual-phase steel," J. Mater. Eng. Perform. 21, 3: 382-387, 2012.

[11]Y. Granbom, Structure and mechanical properties of dual phase steels - An experimental and theoretical analysis. Royal Institute of Technology, Sweden. Ph.D. thesis, 2010.

[12] M. Erdogan and S. Tekeli, "The effect of martensite particle size on tensile fracture of surface-carburised AISI 8620 steel with dual phase core microstructure," Mater. Des. 23, 7: 597-604, 2002.

[13]ASTM, "ASTM E23-16b: Standard Test Methods for Notched Bar Impact Testing of Metallic Materials," ASTM B. Stand., Vol. i: 126, 2016.

[14]G. R. Speich, V. A. Demarest, and R. L. Miller, "Formation of
Austenite During Intercritical Annealing of Dual-Phase Steels," Metall. Mater. Trans. A, 12, 8: 1419-1428, 1981.

[15]G. Krauss, "Steels processing, structure, and performance," Materials Park, Ohio : ASM International, p.234-249, 2005.

[16]C. Peng-Heng and A. G. Preban, "The effect of ferrite grain size and martensite volume fraction on the tensile properties of dual phase steel," Acta Metall. 33, 5: 897-903, 1985.

[17]G. Rosenberg, I. Sinaiová, and L. Juhar, "Effect of microstructure on mechanical properties of dual phase steels in the presence of stress concentrators," Mater. Sci. Eng. A, 582: 347-358, 2013.

[18]Z. Zhao, T. Tong, J. Liang, H. Yin, A. Zhao, and D. Tang, "Microstructure, mechanical properties and fracture behavior of ultra-high strength dual-phase steel," Mater. Sci. Eng. A, 618: 182$188,2014$.

[19]P. Movahed, S. Kolahgar, S. P. H. Marashi, M. Pouranvari, and N. Parvin, "The effect of intercritical heat treatment temperature on the tensile properties and work hardening behavior of ferritemartensite dual phase steel sheets," Mater. Sci. Eng. A, 518, 1-2: $1-6,2009$.

[20]A. P. Pierman, O. Bouaziz, T. Pardoen, P. J. Jacques, and L. Brassart, "The influence of microstructure and composition on the plastic behaviour of dual-phase steels," Acta Mater., 73: 298-311, 2014.

[21]N. Saeidi and A. Ekrami, "Comparison of mechanical properties of martensite/ferrite and bainite/ferrite dual phase 4340 steels," Mater. Sci. Eng. A, 523, 1-2: 125-129, 2009.

[22]N. Saeidi and A. Ekrami, "Impact properties of tempered bainiteferrite dual phase steels," Mater. Sci. Eng. A, 527, 21-22: 5575$5581,2010$.

[23] S. S. M. Tavares, P. D. Pedroza, J. R. Teodósio, and T. Gurova, "Mechanical properties of a quenched and tempered dual phase steel," Scr. Mater., 40, 8: 887-892, 1999.

[24] L. Shi et al., "Improved toughness and ductility in ferrite/acicular ferrite dual-phase steel through intercritical heat treatment," Mater. Sci. Eng. A, 590: 7-15, 2014.

[25] J. Y. Koo and G. Thomas, "Metallurgical factor controlling impact properties of two dual phase steels," Scr. Metall. 13, 12: 1141$1145,1979$.

[26]Y. J. Chao, J. D. Ward, and R. G. Sands, "Charpy impact energy, fracture toughness and ductile-brittle transition temperature of dualphase 590 Steel," Mater. Des. 28, 2: 551-557, 2007.

[27]Y. Mazaheri, A. Kermanpur, and A. Najafizadeh, "Nanoindentation 
D. Avendaño-Rodríguez, J.D. Granados, E. Espejo-Mora, L. Mujica-Roncery and R. Rodríguez-Baracaldo/

Journal of Engineering Science and Technology Review 11 (6) (2018) 174 - 181

study of ferrite-martensite dual phase steels developed by a new thermomechanical processing," Mater. Sci. Eng. A, 639: 8-14, 2015.

[28]Q. Lai, O. Bouaziz, M. Gouné, A. Perlade, Y. Bréchet, and T. Pardoen, "Microstructure refinement of dual-phase steels with $3.5 \mathrm{wt} \% \mathrm{Mn}$ : Influence on plastic and fracture behavior," Mater. Sci. Eng. A, 638: 78-89, 2015.

[29]Q. Lai et al., "Damage and fracture of dual-phase steels: Influence of martensite volume fraction," Mater. Sci. Eng. A, 646: 322-331, 2015.

[30] J. Zhang, H. Di, Y. Deng, and R. D. K. Misra, "Effect of martensite morphology and volume fraction on strain hardening and fracture behavior of martensite-ferrite dual phase steel," Mater. Sci. Eng. A, 627: 230-240, 2015. 